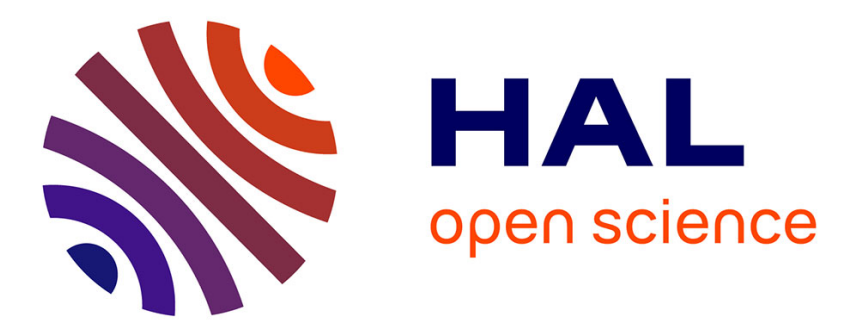

\title{
Alternariol induces abnormal nuclear morphology and cell cycle arrest in murine RAW 264.7 macrophages.
}

Anita Solhaug, Jorn A. Holme, Kaisa Haglund, Béatrice Dendele, Odile

Sergent, James J. Pestka, Dominique Lagadic-Gossmann, Gunnar Sundstol Eriksen

\section{To cite this version:}

Anita Solhaug, Jorn A. Holme, Kaisa Haglund, Béatrice Dendele, Odile Sergent, et al.. Alternariol induces abnormal nuclear morphology and cell cycle arrest in murine RAW 264.7 macrophages.. Toxicology Letters, 2013, 219 (1), pp.8-17. 10.1016/j.toxlet.2013.02.012 . inserm-00871659

\section{HAL Id: inserm-00871659 https://www.hal.inserm.fr/inserm-00871659}

Submitted on 11 Apr 2014

HAL is a multi-disciplinary open access archive for the deposit and dissemination of scientific research documents, whether they are published or not. The documents may come from teaching and research institutions in France or abroad, or from public or private research centers.
L'archive ouverte pluridisciplinaire HAL, est destinée au dépôt et à la diffusion de documents scientifiques de niveau recherche, publiés ou non, émanant des établissements d'enseignement et de recherche français ou étrangers, des laboratoires publics ou privés. 


\section{Alternariol induces abnormal nuclear morphology and cell cycle arrest in murine RAW 264.7 macrophages.}

A Solhaug ${ }^{1,2}$, JA Holme ${ }^{3}$, K Haglund ${ }^{4}$, B Dendele ${ }^{5,6}$, O Sergent ${ }^{5,6}$, J Pestka ${ }^{7}$, D LagadicGossmann $^{5,6}$, GS Eriksen ${ }^{1}$

${ }^{1}$ Norwegian Veterinary Institute, Oslo, Norway, ${ }^{3}$ Norwegian Institute of Public Health, Division of Environmental Medicine, Oslo, Norway, ${ }^{4}$ Department of Biochemistry, Institute for cancer Research, Oslo University Hospital, Centre for Cancer Biomedicine, Faculty of Medicine, University of Oslo, Montebello, Oslo, Norway, ${ }^{5}$ Inserm U1085, IRSET, Rennes, France, ${ }^{6}$ Université Rennes 1, SFR BIOSIT, Rennes, France, ${ }^{7}$ Michigan State University, Department of Food Science and Human Nutrition, East Lansing, USA.

${ }^{2}$ Corresponding author:

Dr. Anita Solhaug, PhD

Norwegian Veterinary Institute

P.O.BOX 750 Centrum, 0106 Oslo

Tel: +47 23216214; Fax: +47 23216201

E-mail: Anita.Solhaug@ vetinst.no

Running title: $\mathrm{AOH}$ induces abnormal nuclear morphology and cell cycle arrest. 


\begin{abstract}
The mycotoxin alternariol $(\mathrm{AOH})$, a frequent contaminant in fruit and cereal products, is known to induce DNA damage with subsequent cell cycle arrest. Here we elucidated the effects of $\mathrm{AOH}$ on stages of cell cycle progression using the RAW 264.7 macrophage model. $\mathrm{AOH}$ resulted in an accumulation of cells in the $\mathrm{G}_{2} / \mathrm{M}$-phase $(4 \mathrm{~N})$. Most cells exhibited a large $G_{2}$ nucleus whereas numbers of true mitotic cells were reduced relative to control. Both cyclin B1 and p-cdc2 levels increased, while cyclin B1 remained in the cytoplasm; suggesting arrest in the $\mathrm{G}_{2} / \mathrm{M}$ transition point. Remarkably, after exposure to $\mathrm{AOH}$ for $24 \mathrm{~h}$, most of the cells exhibited abnormally shaped nuclei, as evidenced by partly divided nuclei, nuclear blebs, polyploidy and micronuclei (MN). AOH treatment also induced abnormal Aurora B bridges, suggesting that cytokinesis was interfered within cells undergoing karyokinesis. A minor part of the resultant $\mathrm{G}_{1}$ tetraploid $(4 \mathrm{~N})$ cells re-entered the $\mathrm{S}$-phase and progressed to $8 \mathrm{~N}$ cells.
\end{abstract}

Keywords: alternariol, cell cycle, topoisomerase II $\alpha$, polyploidy 


\section{Abbreviations:}

AOH (alternariol),AME (alternariol monomethyl ether), ATM (ataxia telangiectasia mutated), 12-DSA (12-Doxyl Stearic Acid), ATR (ATM-Rad3-related), BSA (bovine serum albumin), Chk-1/2 (checkpoint kinase 1/2), DMEM (Dulbecco's Modified Eagle Medium), DSBs (DNA double stranded breaks), ECACC (European Collection of Cell Cultures), EPR (electron paramagnetic resonance), FBS (fetal bovine serum), HRP (horseradish peroxidase), MN (micronuclei), PBS (phosphate buffered saline), PEM (PIPES, EGTA, MgSO4 buffer), PFA (paraformaldehyde), PI (propidium iodide), PIPES (1,4 piperazinediethanesulfonic acid), ROS (reactive oxygen species), SSBs (DNA single stranded breaks), TBS (TRIS-buffered saline), TBST (TBS-tween), TeA (tenuazonic acid), TEM (transmission electron microscopy), Topo (topoisomerase) 


\section{Introduction}

Mycotoxins, biologically active secondary fungal metabolites, are found as contaminants of food and pose a major risk for disease in humans and animals. The mycotoxin alternariol $(\mathrm{AOH})$ is produced by the fungi of the Alternaria genus, common contaminants of fruit, vegetables and cereal products. In vitro studies have reported that AOH causes DNA damage (Fehr et al., 2009; Pfeiffer et al., 2007) and mutations (Brugger et al., 2006). AOH has the potential to act as a topoisomerase (topo) II $\alpha$ poison (Fehr et al., 2009), which might contribute to its ability to cause DNA double strand breaks (DSBs). In a recent study, we found that $\mathrm{AOH}$ induced reactive oxygen species (ROS) and oxidative DNA damage in addition to DNA breaks in RAW 264.7 macrophages (Solhaug et al., 2012). The DNA damage response was associated with reduced cell proliferation resulting in an accumulation of cells in $\mathrm{G}_{2} / \mathrm{M}(4 \mathrm{~N})$.

While several reports suggest that $\mathrm{AOH}$ induces cell cycle arrest (Brugger et al., 2006; Schreck et al., 2012; Wollenhaupt et al., 2008), a more precise and detailed characterization of the process is still lacking. Cells have various cell cycle checkpoints that ensure that individual phases of the cell cycle are not initiated unless conditions are favorable and previous phases have been successfully completed (Bartek et al., 2004). These include the $\mathrm{G}_{1} / \mathrm{S}$ (DNA damage checkpoint), $\mathrm{G}_{2}$ (DNA damage checkpoint, decatenation checkpoint), $\mathrm{G}_{2} / \mathrm{M}$ (antephase checkpoint), $\mathrm{M} / \mathrm{A}$ (metaphase/anaphase; spindle assembly checkpoint) and the $\mathrm{G}_{1}$ tetraploidy checkpoint.

The $\mathrm{G}_{1} / \mathrm{S}$ DNA damage checkpoint is often controlled by p53 through its ability to induce p21 expression. The increased level of p21 inhibits both cyclin $\mathrm{E}$ and cyclin A/cdk2 activity which are required for the $G_{1} / S$ phase transition. The $G_{2}$ DNA damage checkpoint is guarded by several pathways (Chin and Yeong, 2010). The PI-3K ataxia telangiectasia mutated protein kinase (ATM) mainly responds to DSBs, while ataxia-telangiectasia and RAD3 related (ATR) respond to DNA single stranded breaks (SSBs) (Lee and Paull, 2007; Nam and Cortez, 2011). The ATR might also be activated secondary to ATM, after prior processing of the DSBs to SSBs (Smith et al., 2010). ATR/ATM then activate checkpoint kinase 1 and/or 2 (chk-1/2) and the cdc $25 \mathrm{C}$ phosphatase to rapidly prevent entry into mitosis by depressing the activity of cyclin A- and B-dependent kinases. These pathways quickly induce a transient block in $\mathrm{G}_{2}$, although a more sustained block can be induced via the transcription-dependent p53/p21 
pathway (Mikhailov et al., 2005; Taylor and Stark, 2001). Another checkpoint in the $\mathrm{G}_{2}$ phase is the decatenation checkpoint (Damelin and Bestor, 2007). Topo II $\alpha$ activity is required to remove cations that form between sister DNA molecules, as a consequence of their replication. Because these cations physically link the sister DNAs, they must be removed to allow chromosome condensation in prophase and chromosome segregation in anaphase. The presence of a decatenation checkpoint that is independent of DNA damage has been supported by a variety of studies (Damelin et al., 2005; Nakagawa et al., 2004). The concept is however still controversial as the topo II inhibitor ICRF-193 has been shown to activate DNA damage signaling in some cancer cell lines (Park and Avraham, 2006).

Mitosis can be subdivided into karyokinesis (prophase, prometaphase, metaphase, anaphase, telophase) and cytokinesis. Mitosis is often defined as beginning of the chromosome condensation; however this is a gradual process that is shortly initiated after the S-phase as the Aurora kinases begin to phosphorylate histones. Furthermore, up to a point, the process of prophase chromosome condensation is reversible. Once this point (also called antephase) is passed, the cell is committed to divide and undergo nuclear envelope breakdown (Rieder, 2011). Some consider the antephase to be the last checkpoint for entering into mitosis (Chin and Yeong, 2010). It appears, however, to be distinct from the decatenation checkpoint (Damelin and Bestor, 2007). In order to minimize the production of aneuploid progeny during mitosis, cells have evolved a checkpoint in the M/A transition, the spindle assembly checkpoint, that delays chromatid separation in the presence of kinetochores that are not attached to microtubules and can delay anaphase for several hours (Rieder, 2011). Cytokinesis is the physical separation of two daughter cells during the cell division (Barr and Gruneberg, 2007). Many different types of errors in cell division can lead to failure of cytokinesis and the generation of tetraploid cells. These cells are suggested to be arrested in $\mathrm{G}_{1}$ by the tetraploidy checkpoint via a p53- dependent mechanism (Ganem and Pellman, 2007).

The immune system is a potential target for adverse health effects of mycotoxins such as trichothecenes, with low doses of the toxin having immunostimulatory effects and high doses causing immunosuppression (Pestka, 2010). Interestingly, proliferation of macrophages rather than recruitment from the blood has recently been shown to be important in type 2 immune responses (Jenkins et al., 2011). As mycotoxins most often are found in mixtures, it is important to also examine the potential immunotoxic effects of other co-occurring mycotoxins including AOH (Kosiak et al., 2004) on immune cells. The RAW 264.7 murine macrophage 
cell line is often used to study effects of mycotoxins on immune cells (Zhou et al., 2005). The model was recently successfully used in our study on AOH (Solhaug et al., 2012), demonstrating a functional DNA damage response including an adequate p53 response. The aim of the present study is to determine how AOH impairs cell cycle progression. The concentrations of $\mathrm{AOH}$ used in this study are in the same range that causing DNA damage previously published by us and others (Brugger et al., 2006; Fehr et al., 2009; Pfeiffer et al., 2007; Solhaug et al., 2012).

\section{Materials and Methods}

\subsection{Reagents and chemicals}

RNAse (Purelink ${ }^{\mathrm{TM}}$ RNase A), bovine serum albumin (BSA) and gels and buffers for Western blotting (NuPAGE system) were all purchased from Invitrogen (Life Technology, Carlsbad, CA, USA). Propidium iodide (PI), DAPI and Hoechst 33342 were from Molecular Probes (Life Technology, Eugene, OR, USA). Lysisbuffer was from Cell Signaling (Beverly, MA, USA). Dulbecco's Modified Eagle Medium (DMEM), Penicillin/Streptomycin and Fetal bovine serum (FBS) were from Lonza (Verviers, Belgium), Bio-RAD DC protein assay from Bio-Rad Laboratories Inc (Hercules, CA, USA). Super signal west dura chemoluminiscence system was from, Pierce Thermo Scientific (Rockford, IL, USA). AOH was from SigmaAldrich (St.Louis, MO, USA). Cyclin B1, p-cyclin B1 (S147), cyclin D1, p27, p-cdc-2 (Tyr15), $\beta$-Actin Rabbit mAb HRP conjugate and Anti-Rabbit IgG HRP-linked antibody were purchased from Cell Signaling. Histone H3 (S28) - Alexa Fluor 647 was from BD biosciences (Franklin lakes, NJ, USA). $\alpha$-tubulin was from Sigma and Aurora B was from Abcam (Cambridge, MA, USA). Anti-rabbit Alexa Fluor 647, anti-mouse Alexa Fluor 647, antirabbit Alexa Fluor 488, anti-mouse-CY3 and Alexa Fluor 488 -conjugated cholera toxin subunit B (Ctx B) were from Molecular Probes.

\subsection{Cell culture and treatments}

The mouse macrophage cell line RAW 264.7 was obtained from European Collection of Cell Cultures (ECACC) and grown in DMEM supplemented with 10\% heat inactivated FBS (FBS; EU standard, Lonza), penicillin $(100 \mathrm{U} / \mathrm{ml})$, and streptomycin $(100 \mu \mathrm{g} / \mathrm{ml})$. Cells were cultured at $37^{\circ} \mathrm{C}$ under $5 \% \mathrm{CO}_{2}$ in a humidified incubator and kept in logarithmic growth 
phase at $10^{6}-10^{7}$ cells $/ 75 \mathrm{~cm}^{2}$ through routine sub-culturing twice a week by scraping, according to standard ECACC protocol. For measurement of proliferation, the cells were plated on UpCell plates (Nunc, Rochester, NY, USA). These plates are unique in that the surface is temperature-responsive and allow cells to detach without the use of cell scrapers at temperatures below $32^{\circ} \mathrm{C}$. For harvesting the plates were put on ice for $10 \mathrm{~min}$ to allow detachment. Cells were seeded at a density between 20000 and 45000 cells $/ \mathrm{cm}^{2}$ the day before the experiment and medium refreshed before exposures. This cell-density allowed the cells to grow without reaching confluence during the experiments. $\mathrm{AOH}$ was dissolved in DMSO and the final concentration of solvent in cell culture was $0.1 \%$. Appropriate controls containing the same amount of solvent were included in each experiment.

\subsection{Cell growth}

RAW 264.7 cells were cultured on UpCell dishes and treated with $\mathrm{AOH}$ and harvested as described above Cell growth was measured by counting number of cells using a flow cytometer, Accuri C6 (BD bioscience). Debris was excluded from the analysis through gating (FCS-A vs. SSC-A).

\subsection{Cell cycle, polyploidy}

For cell cycle analysis, RAW 264.7 cells were harvested by scraping, washed with PBS and fixed with ice-cold $70 \% \mathrm{EtOH}$ overnight at $-20^{\circ} \mathrm{C}$. The cells were then washed with PBS, incubated with PI $(10 \mu \mathrm{g} / \mathrm{ml}) / \mathrm{RNase} \mathrm{A}(100 \mu \mathrm{g} / \mathrm{ml})$ in PBS for $30 \mathrm{~min}$ at $37^{\circ} \mathrm{C}$ before analyses on a flow cytometer, Accuri C6. Single cells were gated and a minimum of 10000 cells acquired and analysed by using the FL2-A (585/40) filter. Data acquired were analysed by Accuri CFlow Plus. For analysis of polyploidy, the cells were treated with trypsin and stained with PI according to the method of Vindelov (Vindelov et al., 1983), and analysed by flow cytometry. Single cells were gated as shown in Suppl. Fig S1, and a minimum of 30000 cells acquired and analysed by using the FL2-A (585/40) filter.

\subsection{Western Blot}


Preparation of cell lysate and Western blot were done as previously described (Solhaug et al., 2012).

\subsection{Measurement of intracellular proteins by flow cytometry}

Harvesting and fixing the cells was done as previously described (Solhaug et al., 2012). For staining, the cells were incubated with primary antibody for $2 \mathrm{~h}$ followed with secondary antibody conjugated to Alexa Fluor 647 for $1 \mathrm{~h}$ at ambient temperature. For analyses of Histone H3 (S28), cells were incubated with Histone H3 (S28)-antibody Alexa Fluor 647 conjugant $1 \mathrm{~h}$ at room temperature. After staining, the cells were washed twice with $0.5 \%$ BSA/PBS, resuspended in PBS and analysed by flow cytometry. For analysis of cell cycle distribution in addition to protein expression, the cells were first stained with the antibody of interest, then stained with PI/RNase, as described above and analysed by flow cytometry.

\subsection{Fluorescence and confocal microscopy}

Cells were plated on poly(L)lysine coated coverslips (BD Biosciences). After AOH exposure, the cells were fixed in $4 \%$ PFA for 10 min at room temperature, permeabilized in PEM buffer (pH 6.8; 80 mM PIPES (1,4 piperazinediethanesulfonic acid), $5 \mathrm{mM}$ EGTA, $1 \mathrm{mM} \mathrm{MgCl}_{2}$ ) containing $0.05 \%$ saponin for $5 \mathrm{~min}$, rinsed briefly and blocked with $50 \mathrm{mM} \mathrm{NH}{ }_{4} \mathrm{Cl}$ in $\mathrm{PBS}$ for $15 \mathrm{~min}$ at room temperature. Cells were stained with rabbit anti-Aurora B, mouse anti- $\alpha$ tubulin or anti-cyclin B1 diluted in PBS containing $0.05 \%$ saponin for $2 \mathrm{~h}$ at room temperature, washed $3 \times 5$ min with $\mathrm{PBS} / 0.05 \%$ saponin. Cells were then incubated with secondary fluorochrom-conjugated antibodies diluted in PBS/0.05\% saponin, for $45 \mathrm{~min}$ at room temperature. Cells were then again washed 3 times for $5 \mathrm{~min}$ with PBS, the nuclei stained with Hoechst $33342(1 \mu \mathrm{g} / \mu \mathrm{l})$ and the coverslips were mounted with mowiol (Calbiochem). Pictures were taken with a fluorescence microscope (Nicon Eclipse 80i, equipped with a DS-Ri1 camera) or a Zeiss LSM 5 DUO laser scanning confocal microscope (Carl Zeiss, Inc.) equipped with NeoFluar $63 \times / 1.4$ NA and $100 \times / 1.45$ NA oil immersion objectives and a Plan Apochromat $20 \times / 0.8 \mathrm{NA}$ at $20^{\circ} \mathrm{C}$. Image processing and analysis were done using the Zeiss LSM 510 software (Version 3.2, Carl Zeiss, Inc.). Analysis of nuclear morphology and micronuclei (MN) by nuclear staining: Following exposure, the cells were fixed in ice cold methanol (90\%) for 10 in on ice. The cells were then stained with Hoechst 
$33342(10 \mu \mathrm{g} / \mu \mathrm{l})$ and mounted with mowiol (Calbiochem). Pictures were taken with a fluorescence microscope (Nikon Eclipse 80i, equipped with a DS-Ri1 camera).

\subsection{Transmission electron microscopy (TEM)}

Following drug exposure the cells were rinsed with $0.15 \mathrm{M} \mathrm{Na}$ cacodylate buffer and fixed by drop wise addition of glutaraldehyde $(2.5 \%)$ for $1 \mathrm{~h}$. After fixation, the specimens were rinsed several times with $0.15 \mathrm{M} \mathrm{Na}$ cacodylate buffer and post fixed with $1.5 \%$ osmium tetroxide for $1 \mathrm{~h}$. After further rinsing with cacodylate buffer, the samples were dehydrated through a series of graded ethanol from 70 to $100 \%$. The specimens were infiltrated in a mixture of acetone-Eponate (50/50) for $3 \mathrm{~h}$, then in pure Eponate for $16 \mathrm{~h}$. Finally, the specimens were embedded in DMP30-Eponate for $24 \mathrm{~h}$ at $60^{\circ} \mathrm{C}$. Sections $(0.5 \mu \mathrm{m})$ were cut on a LEICA UC7 microtome and stained with toluidine blue. Ultra-thin sections $(90 \mathrm{~nm})$ were obtained, collected onto copper grids and counterstained with $4 \%$ uranyl acetate then with lead citrate. Examination was performed with JEOL 1400 electron microscope operated at $120 \mathrm{kV}$.

\subsection{GM1 immunofluorescence assay}

RAW 264.7 cells were fixed and stained with cholera toxin subunit B - Alexa Fluor 488 as previously described (Gammelsrud et al., 2012). Pictures were captured with a DMRXA Leica microscope and a COHU high performance CCD camera using Metavue software.

\subsection{Determination of membrane fluidity}

The membrane fluidity of bulk membranes was determined by a spin-labelling method using electron paramagnetic resonance (EPR). After treatment, cells collected in PBS were incubated with $50 \mu \mathrm{g} / \mathrm{mL}$ 12-Doxyl Stearic Acid (12-DSA) spin label for $15 \mathrm{~min}$ at $37^{\circ} \mathrm{C}$ and then were washed 3 times with cold PBS to eliminate the free spin label. The final pellet was kept on ice to prevent any spin label reduction before analysing the EPR spectrum at room temperature $\left(20^{\circ} \mathrm{C}\right)$ using a Bruker ECS 106 spectrometer $(9.82 \mathrm{GHz}$ frequency, $20 \mathrm{~mW}$ microwave power, $1.771 \mathrm{G}$ modulation amplitude, and $100 \mathrm{kHz}$ modulation frequency; Bruker Spectrospin). The values of inner hyperfine-splitting EPR spectra, typical for 12-DSA 
spin label, were used to calculate the membrane order parameter S. A decrease in the membrane order parameter reflects an increase in membrane fluidity.

\subsection{Statistical analysis}

Differences between treatments were analysed statistically by using t-test for unpaired data, if not others are stated.

\section{Results}

\subsection{AOH reduces cell growth and causes cell cycle arrest}

To assess the effects of $\mathrm{AOH}$ on cell growth, RAW 264.7 were exposed to various concentrations of the toxin for 24 and $48 \mathrm{~h}$, and the number of viable cells counted by flow cytometer. The data in Fig 1 shows that $15 \mu \mathrm{M}$ AOH reduced the number of cells by more than $50 \%$ after $24 \mathrm{~h}$ when compared to control. At $48 \mathrm{~h}$ the number of cells had started to increase again, but was still only $30 \%$ when compared to control. The effects of $\mathrm{AOH}$ on-cell growth at higher concentrations were even clearer. Further analyses of the cell cycle showed that $30 \mu \mathrm{M}$ of $\mathrm{AOH}$ first resulted in an accumulation of cells in S-phase later ending up as cells in the $\mathrm{G}_{2} / \mathrm{M}(4 \mathrm{~N})$ (Fig $2 \mathrm{~A}$ and $\mathrm{B}$ ). The lower concentration $(15 \mu \mathrm{M})$ also induced an early accumulation of cells in the $S$ phase, but no $\mathrm{G}_{2} / \mathrm{M}$ arrest at later time points was seen. . Taken together, these data suggest that $\mathrm{AOH}$ treatment interferes with cell proliferation and causes an accumulation of cells in $4 \mathrm{~N}$.

\subsection{AOH reduces the number of mitotic cells}

To ascertain whether $4 \mathrm{~N}$ cells were arrested at $\mathrm{G}_{2} / \mathrm{M} \quad\left(\mathrm{G}_{2} /\right.$ mitosis $)$ or at the metaphase/anaphase (M/A) transition points, cells were analysed by flow cytometry after staining with the mitotic marker phosphorylated histone H3 (S28; phosphorylated when proceeding from prophase to anaphase). Interestingly, numbers of mitotic cells were markedly down regulated throughout the $48 \mathrm{~h}$ exposure period beginning at $4 \mathrm{~h}$ after $\mathrm{AOH}(30 \mu \mathrm{M})$ exposure (Fig 3), which was verified by fluorescence microscopy (cells with properly condensed chromosomes; data not shown). 


\section{$3.3 \mathrm{AOH}$ affects regulators of the cell cycle}

To further characterize the $\mathrm{AOH}$-induced $\mathrm{G}_{2} / \mathrm{M}$ arrest, we measured expression of cyclin $\mathrm{B} 1$ and $\mathrm{p}-\mathrm{cdc} 2$. Activation of the cyclin B1-cdc2 complex and thus entry into mitosis, involves both dephosphorylation of cdc2 and phosphorylation of cyclin B1. AOH exposure $(30 \mu \mathrm{M})$ induced an up regulation of both cyclin B1 and p-cdc2 as observed by Western blot (Fig 4AB) and flow cytometry (Fig 4C), which indicated a deactivated cyclin B1-cdc2 complex and an arrest in the $G_{2} / M$ transition point. Furthermore, phosphorylation of cyclin B1 at site S147 (Fig 4A), was not observed, which is suggestive of the G2/M arrest. Flow cytometric analysis verified that cells with elevated cyclin B1 were in the (4N) phase (Fig 4D). Additionally, fluorescence microscopy revealed that cyclin B1 was mainly located in the cytoplasm in AOH-exposed cells (Fig 4E), which is typical of arrest in the $G_{2} / M$ transition point. A minor fraction of the 4N cells had low levels of cyclin B1 (Fig 4D) which could represent mitotic cells and/ or tetraploid $G_{1}$ cells. In contrast to cyclin B1, cyclin D1 and p27 which is important for the $G_{1} / S$ restriction point, was found to be unchanged after $A O H$ exposure (Suppl. Fig S2). Altogether, these data strongly suggest a reduced activity of the cyclin $\mathrm{B} 1 / \mathrm{cdc} 2$ complex in the presence of $\mathrm{AOH}$ resulting in an arrest in the $\mathrm{G}_{2} / \mathrm{M}$ transition point.

\subsection{AOH induces morphological changes of the nucleus}

Fluorescence microscopy following staining with Hoechst 33342 revealed that most AOHtreated cells (24-72 h) contained nuclei with increased size and abnormal morphology (Fig 5). These changes included partly separated nuclei, nuclear blebs and clearly separated nuclei; and cells with MN (Fig 5A-C). The morphological changes were further verified by analysis using transmission electron microscopy (TEM; Fig 5D).

To ascertain if the tetraploid (4N) cells could re-enter the S-phase, we next examined the level of $>4 \mathrm{~N}$ cells by flow cytometry. After $72 \mathrm{~h}$ exposure of AOH $(30 \mu \mathrm{M})$, about $2 \%$ exceeded 4N, equivalent to a 7-fold increase compared to control (Fig 6). The majority of these cells were $8 \mathrm{~N}$. Bi- or multi-nucleated cells may often be a result of failures in the cytokinesis (Barr 
and Gruneberg, 2007). Aurora B was thus used as a marker for intercellular bridges of cells undergoing cytokinesis to study this process in more detail. Following $24 \mathrm{~h}$ of $\mathrm{AOH}(30 \mu \mathrm{M})$ exposure, we found abnormal intercellular bridges stained by Aurora B, where three or four dividing nuclei appeared to be connected by Aurora B-positive bridges, at levels that correlated with the later appearance of polynucleated (8N) cells (Fig 7; abnormal Aurora B bridges: control: $0.0 \%, \mathrm{AOH}: 1.7 \%)$.

\subsection{Membrane remodeling}

Distinct membrane lipid domains, also called membrane rafts, have been reported to play an essential role for the cytokinesis (Szafer-Glusman et al., 2008). The effect of AOH on the organization of lipid rafts was studied by fluorescence microscopy, using GM1 as a marker. GM1 is a type of ganglioside found in the plasma membrane rafts and acts as the site of binding for cholera toxin fragment B. The distribution of GM1 in cells exposed to AOH (30 $\mu \mathrm{M}, 24 \mathrm{~h}$ ) was somewhat reduced compared to control cells (Suppl. Fig S3A). To explore this possibility further, the membrane fluidity of bulk membranes was determined by a spinlabelling method using (EPR). As evidenced in the data presented in suppl. Fig S3B, AOH appeared to induce slightly increase in the membrane fluidity. Thus a possible membrane effect cannot be excluded.

\section{Discussion}

Inhibition of cell cycle progression is often linked to DNA damage and its resultant repair response. It well known that $\mathrm{AOH}$ is genotoxic (Fehr et al., 2009; Pfeiffer et al., 2007), and recently we reported that $\mathrm{AOH}$ generates DNA strand breaks as well as oxidative DNA damage in the RAW 264.7 cells (Solhaug et al., 2012). The results presented here are the first to report that $\mathrm{AOH}$ causes a specific arrest in the $\mathrm{G}_{2} / \mathrm{M}$ transition point that is associated with a reduced activity of the cyclin $\mathrm{B} 1 / \mathrm{cdc} 2$ complex. The $\mathrm{AOH}$-induced cell cycle arrest was followed by marked morphological changes including nuclear abnormalities.

An $\mathrm{AOH}-$ induced accumulation of cells in the $\mathrm{G}_{2} / \mathrm{M}(4 \mathrm{~N})$ is in accordance with most of the previous findings (Brugger et al., 2006; Burkhardt et al., 2012; Solhaug et al., 2012) although an accumulation of cells in $\mathrm{G}_{1}$ (Wollenhaupt et al., 2008) has also been reported. The arrest in 
$\mathrm{G}_{2} / \mathrm{M}$ transition point is often a result of DNA damage as unrepaired damage may end up as gene mutations or larger chromosomal rearrangements. We have previously reported that $\mathrm{AOH}-\mathrm{induced}$ DNA damage leads to the induction of signaling cascades including chk1 and chk2 with a subsequent activation of p53 (Solhaug et al., 2012). Activation of chk1 and 2 is known to be an important mediator of the $\mathrm{G}_{2} / \mathrm{M}$ DNA damage checkpoint, by inhibiting the cdc25 phosphatase family, therefore maintaining the cdc2/cyclin B1 complex in an inactive cytoplasmic state (Toettcher et al., 2009).

We also observed an increased level of cyclin B1, which is likely due to an increased mRNA expression as previously reported (Solhaug et al., 2012). During normal cell cycle progression, cdc 2 is activated by dephosphorylation of Tyr 15 residue by Cdc 25 phosphatases (Boutros et al., 2006). AOH treatment resulted in an increased phosphorylation of cdc2 at Thr15, which is known to inhibit its kinase activity and are often carried out by Wee1 and Myt1 protein kinases (Mueller et al., 1995; Parker and Piwnica-Worms, 1992). Phosphorylation of cyclin B1 is shown to be central for its nuclear translocation (ToyoshimaMorimoto et al., 2001). AOH did not increase phosphorylation of cyclin B1 (Thr161) and accumulated cyclin B1 still seems to be located in the cytoplasm. This is in agreement with an inactive cdc2/cyclin B1-complex, since active cdc2/cyclin B1 complex is known to be translocated into the nucleus thereby triggering the destruction of the nuclear envelope occurring in late prophase (Gavet and Pines, 2010).

Notably, it has been suggested that cells are not committed to mitosis until late prophase; just before nuclear envelope breakdown, which allows the mitotic spindle to access the chromosomes (Rieder, 2011). Before the cells reach this point, various insults may arrest chromosome condensation, or induce chromosome decondensation and delay the cell in $\mathrm{G}_{2}$. We have previously shown that $\mathrm{AOH}$ treatment led to up regulation of several genes involved in the DNA damage response, such as p21, BRCA1, BRCA2 and PCNA as well as activation (phosphorylation) of p53, H2AX and chk1 and chk2 (Solhaug et al., 2012). Accordingly, the marked DNA damage and DNA damage response suggest that the cells were arrested in the $\mathrm{G}_{2} / \mathrm{M}$ DNA damage checkpoint.

Most interestingly, AOH has been reported to act as a topo II $\alpha$ poison (Fehr et al., 2009). Previously, we proposed that this effect is highly relevant to $\mathrm{AOH}$ induced cell cycle arrest 
(Solhaug et al., 2012). Topo II $\alpha$ is required mainly during the final stages of DNA replication to facilitate chromosome untangling, condensation and segregation during mitosis. This is in agreement with our findings here, that $\mathrm{AOH}$ induces an early increase in S-phase which is followed by a massive G2 arrest. Topo II appears to regulate mitotic progression so that chromosomes can efficiently condense in prophase and be segregated with high fidelity in anaphase (Downes et al., 1994). Topo II poisons are known to stabilize the cleavage complex, which may block DNA replication forks or transcriptional machinery and create DSBs. In contrast, topo II inhibitors prevent the formation of the cleavage complex by intercalating into DNA and inhibiting topo II binding or by stabilizing topo II in a closed-clamp conformation after the ligation step of the catalytic cycle. Previous findings suggest that inhibition of topo II decatenatory activity triggers a $\mathrm{G}_{2}$ checkpoint response, which delays mitotic entry because of insufficient decatenation of daughter chromatids and relies in part on the nuclear exclusion of cyclin B1/cdc2 complexes (Deming et al., 2001; Downes et al., 1994). Cells treated with $\mathrm{AOH}$ for 24-72 h were found to obtain characteristic blebs or heart-shaped nuclei, as they had tried to start division of the nucleus. Interestingly, depletion of topo II $\alpha$ activity by siRNA in human fibroblasts was found to induce an accumulation of cells in $G_{2}$ with a corresponding decrease of mitotic cells. Similar to AOH-treated cells, the fibroblasts had an increased level of nuclear abnormalities such as MN and blebs/heart-shaped nuclei (Bower et al., 2010). In addition, both topo II $\alpha$ inhibitors and poisons, including $\mathrm{AOH}$, are found to induce $\mathrm{MN}$ (Boos and Stopper, 2000; Brugger et al., 2006). These findings suggest that $\mathrm{AOH}$, in addition to inducing DSBs and a DNA damage response (Solhaug et al., 2012) also could interfere with the decatenatory activity of topo II in RAW 264.7 cells. If so, this would lead to insufficient decatenation as well as incomplete condensation of the chromosomes, which then may lead to abnormal nuclei as the cells attempt to divide the nucleus without previous proper chromosomal condensation.

BRCA1, which is also upregulated by AOH (Solhaug et al., 2012), has been found to be required for the decatenation checkpoint together with ATR and Werner helicase (WRN) (Damelin and Bestor, 2007). Interestingly, it is thought that etoposide (topo II $\alpha$ poison) induces DSBs that affects chromatin organization, since it activates ATR-mediated phosphorylation of SMC1 (structural maintenance of chromosomes). SMC1 is a chromosomal protein member of the cohesin complex that enables sister chromatid cohesion until the M/A transition, and plays a role in DNA repair (Watrin and Peters, 2009). In addition, condensin, another SMC complex, together with topo II is required for mitotic chromosome condensation 
(Tapia-Alveal et al., 2010). Furthermore, a recent study found that topo II $\alpha$ itself is required for the decatenation checkpoint to function (Luo et al., 2009). Thus it is likely that AOHtreated cells that may fail to be arrested in the decatenation checkpoint will be arrested in the antephase checkpoint, which is the last checkpoint before entry into mitosis (Chin and Yeong, 2010).

Upon prolonged high dose of $\mathrm{AOH}$ exposure the nuclei of most of the cells were partly or completely divided, suggesting that they could be tetraploid (4N) $\mathrm{G}_{1}$ cells. It is possible for cells to escape from a $\mathrm{G}_{2} / \mathrm{M}$ arrest into a $4 \mathrm{~N} \mathrm{G}_{1}$ stage via a process called mitotic slippage (Rieder and Maiato, 2004). Recent studies using population and time-lapse imaging analyses of cultured immortalized cells expressing specific cell cycle indicators showed a slippage not only from cells which were clearly in mitosis (M/A), but also from $G_{2} / M$ (decatenation and antephase) (Sakaue-Sawano et al., 2011). As judged by the fact that some 4N cells had low cyclin B1 levels, and that prolonged exposure of $\mathrm{AOH}$ increased the level of cells with $8 \mathrm{~N}$ nuclei, some of the cells most probably went through mitotic slippage. However, mitotic slippage and an arrest in the tetraploid checkpoint are not consistent with the inactive cyclin B1/cdc2 complex and unaltered level of cyclin D1 and p27 seen after AOH treatment. In support of this, gene-expressions of several cell cycle regulators associated with a $G_{1}$ cell cycle arrest (cyclin D1, cyclin E and p27) were not altered followed AOH exposure (Solhaug et al., 2012). Thus, depending on the definition, most of the $4 \mathrm{~N}$ cells were not arrested in the $G_{1}$ phase at the tetraploid checkpoint, but rather retained in the $G_{2} / M$ transition point.

Cytokinesis involves the formation of a cleavage furrow, contraction of an actomyosin-based contractile ring, followed by the formation of a thin intercellular bridge that is cut by abscission to finally separate the dividing cells. Aurora B is essential for mitosis and cytokinesis and following furrow ingression it localizes to the intercellular bridge (Barr and Gruneberg, 2007). It has been suggested that Aurora B functions as a sensor that responds to unsegregated chromatin in the cleavage plane to control abscission timing and to protect misssegregating cells against tetraploidization (Steigemann et al., 2009). Furthermore, it has been proposed that topo II ensures proper sister chromatid separation through a direct role in centromere resolution and prevents incorrect microtubule-kinetochore attachments by allowing proper activation of Aurora B kinase (Coelho et al., 2008). Following AOH exposure abnormal Aurora B bridges were observed, with three or four dividing nuclei being connected by Aurora B-positive intercellular bridges. These findings indicate that $\mathrm{AOH}$, in 
the feature of being a topo II $\alpha$ poison, may have the ability to disturb the Aurora B activity, which could lead to polyploid cells via an additional inhibition of cytokinesis.

During cytokinesis, several cytoskeleton rearrangements, membrane trafficking and plasma membrane remodeling occur. Lipid rafts have been shown to play an essential role in central spindle assembly and cleavage furrow ingression (Albertson et al., 2005). Recently it was found that very long chain fatty acids play an essential role, not only in furrow ingression and cytokinesis, but also in proper formation of the central spindle (Szafer-Glusman et al., 2008). Our findings suggest that $\mathrm{AOH}$ may have some effects on membrane rafts, as $\mathrm{AOH}$ appears to both make the GM1 staining more diffuse and increase the bulky membrane fluidity somewhat. However, the possibility that these changes are secondary effects due to the increased cell volume following $\mathrm{AOH}$ exposure cannot be excluded.

\section{Conclusion:}

We report that the $\mathrm{AOH}$-induced arrest in the $\mathrm{G}_{2} / \mathrm{M}$ transition point is mediated by a reduced activity of the cyclin B1/cdc2 complex. The AOH-induced cell cycle arrest, most probably due to DNA damage and incomplete decatenation, was followed by very specific morphological changes.

Conflict of interest statement: The authors declare that there are no conflicts of interest.

Acknowledgments: We want to thank Hans Christian Dalsbotten Aass (Oslo University Hospital) for skillful help with flow cytometric analysis of polyploidy. We wish to thank the Microscopy Rennes Imaging Center of SFR BIOSIT, Université Rennes 1, and Agnès Burel and Marie-Thérèse Lavault for their technical assistance in TEM experiments. Béatrice Dendelé was a recipient of a fellowship from Région Bretagne.

Funding Information: The work was supported by Research Council of Norway through the project: Toxicological characterization of selected secondary fungal metabolites in Norwegian grain. [Grant nr: 185622/V40]. 


\section{References}

Albertson, R., Riggs, B., Sullivan, W., 2005. Membrane traffic: a driving force in cytokinesis. Trends Cell Biol 15, 92-101.

Barr, F.A., Gruneberg, U., 2007. Cytokinesis: placing and making the final cut. Cell 131, 847-860.

Bartek, J., Lukas, C., Lukas, J., 2004. Checking on DNA damage in S phase. Nat Rev Mol Cell Biol 5, 792-804.

Boos, G., Stopper, H., 2000. Genotoxicity of several clinically used topoisomerase II inhibitors. Toxicol Lett 116, 7-16.

Boutros, R., Dozier, C., Ducommun, B., 2006. The when and wheres of CDC25 phosphatases. Current opinion in cell biology 18, 185-191.

Bower, J.J., Karaca, G.F., Zhou, Y., Simpson, D.A., Cordeiro-Stone, M., Kaufmann, W.K., 2010. Topoisomerase Ilalpha maintains genomic stability through decatenation $\mathrm{G}(2)$ checkpoint signaling. Oncogene 29, 4787-4799.

Brugger, E.M., Wagner, J.r., Schumacher, D.M., Koch, K., Podlech, J., Metzler, M., Lehmann, L., 2006. Mutagenicity of the mycotoxin alternariol in cultured mammalian cells. Toxicology Letters 164, 221230.

Burkhardt, B., Jung, S.A., Pfeiffer, E., Weiss, C., Metzler, M., 2012. Mouse hepatoma cell lines differing in aryl hydrocarbon receptor-mediated signaling have different activities for glucuronidation. Arch Toxicol 86, 643-649.

Chin, C.F., Yeong, F.M., 2010. Safeguarding entry into mitosis: the antephase checkpoint. Mol Cell Biol 30, 22-32.

Coelho, P.A., Queiroz-Machado, J., Carmo, A.M., Moutinho-Pereira, S., Maiato, H., Sunkel, C.E., 2008. Dual role of topoisomerase II in centromere resolution and aurora B activity. PLoS Biol 6, e207.

Damelin, M., Bestor, T.H., 2007. The decatenation checkpoint. Br J Cancer 96, 201-205.

Damelin, M., Sun, Y.E., Sodja, V.B., Bestor, T.H., 2005. Decatenation checkpoint deficiency in stem and progenitor cells. Cancer Cell 8, 479-484.

Deming, P.B., Cistulli, C.A., Zhao, H., Graves, P.R., Piwnica-Worms, H., Paules, R.S., Downes, C.S., Kaufmann, W.K., 2001. The human decatenation checkpoint. Proc Natl Acad Sci USA 98, 1204412049.

Downes, C.S., Clarke, D.J., Mullinger, A.M., Gimenez-Abian, J.F., Creighton, A.M., Johnson, R.T., 1994. A topoisomerase II-dependent G2 cycle checkpoint in mammalian cells. Nature 372, 467-470.

Fehr, M., Pahlke, G., Fritz, J., Christensen, M.O., Boege, F., Altemoller, M., Podlech, J., Marko, D., 2009. Alternariol acts as a topoisomerase poison, preferentially affecting the llalpha isoform. Mol Nutr Food Res 53, 441-451.

Gammelsrud, A., Solhaug, A., Dendele, B., Sandberg, W.J., Ivanova, L., Kocbach, B.A., LagadicGossmann, D., Refsnes, M., Becher, R., Eriksen, G., Holme, J.A., 2012. Enniatin B-induced cell death and inflammatory responses in RAW 267.4 murine macrophages. Toxicol Appl Pharmacol 261, 74-87. Ganem, N.J., Pellman, D., 2007. Limiting the proliferation of polyploid cells. Cell 131, 437-440.

Gavet, O., Pines, J., 2010. Activation of cyclin B1-Cdk1 synchronizes events in the nucleus and the cytoplasm at mitosis. J Cell Biol 189, 247-259.

Jenkins, S.J., Ruckerl, D., Cook, P.C., Jones, L.H., Finkelman, F.D., van, R.N., MacDonald, A.S., Allen, J.E., 2011. Local macrophage proliferation, rather than recruitment from the blood, is a signature of TH2 inflammation. Science 332, 1284-1288.

Kosiak, B., Torp, M., Skjerve, E., Andersen, B., 2004. Alternaria and Fusarium in Norwegian grains of reduced quality--a matched pair sample study. Int J Food Microbiol 93, 51-62.

Lee, J.H., Paull, T.T., 2007. Activation and regulation of ATM kinase activity in response to DNA double-strand breaks. Oncogene 26, 7741-7748.

Luo, K., Yuan, J., Chen, J., Lou, Z., 2009. Topoisomerase Ilalpha controls the decatenation checkpoint. Nat Cell Biol 11, 204-210. 
Mikhailov, A., Shinohara, M., Rieder, C.L., 2005. The p38-mediated stress-activated checkpoint. A rapid response system for delaying progression through antephase and entry into mitosis. Cell Cycle 4, 57-62.

Mueller, P.R., Coleman, T.R., Kumagai, A., Dunphy, W.G., 1995. Myt1: a membrane-associated inhibitory kinase that phosphorylates Cdc2 on both threonine-14 and tyrosine-15. Science 270, 8690.

Nakagawa, T., Hayashita, Y., Maeno, K., Masuda, A., Sugito, N., Osada, H., Yanagisawa, K., Ebi, H., Shimokata, K., Takahashi, T., 2004. Identification of decatenation G2 checkpoint impairment independently of DNA damage G2 checkpoint in human lung cancer cell lines. Cancer Res 64, 48264832.

Nam, E.A., Cortez, D., 2011. ATR signalling: more than meeting at the fork. Biochem J 436, 527-536.

Park, I., Avraham, H.K., 2006. Cell cycle-dependent DNA damage signaling induced by ICRF-193 involves ATM, ATR, CHK2, and BRCA1. ExpCell Res 312, 1996-2008.

Parker, L.L., Piwnica-Worms, H., 1992. Inactivation of the p34cdc2-cyclin B complex by the human WEE1 tyrosine kinase. Science 257, 1955-1957.

Pestka, J.J., 2010. Deoxynivalenol: mechanisms of action, human exposure, and toxicological relevance. Arch Toxicol 84, 663-679.

Pfeiffer, E., Eschbach, S., Metzler, M., 2007. Alternaria toxins: DNA strand-breaking activity in mammalian cells in vitro. Mycotoxin Research 23, 152-157.

Rieder, C.L., 2011. Mitosis in vertebrates: the G2/M and M/A transitions and their associated checkpoints. Chromosome Res 19, 291-306.

Rieder, C.L., Maiato, H., 2004. Stuck in division or passing through: what happens when cells cannot satisfy the spindle assembly checkpoint. Dev Cell 7, 637-651.

Sakaue-Sawano, A., Kobayashi, T., Ohtawa, K., Miyawaki, A., 2011. Drug-induced cell cycle modulation leading to cell-cycle arrest, nuclear mis-segregation, or endoreplication. BMC cell biology $12,2$.

Schreck, I., Deigendesch, U., Burkhardt, B., Marko, D., Weiss, C., 2012. The Alternaria mycotoxins alternariol and alternariol methyl ether induce cytochrome P450 1A1 and apoptosis in murine hepatoma cells dependent on the aryl hydrocarbon receptor. Archives of toxicology 86, 625-632.

Smith, J., Tho, L.M., Xu, N., Gillespie, D.A., 2010. The ATM-Chk2 and ATR-Chk1 pathways in DNA damage signaling and cancer. Adv Cancer Res 108, 73-112.

Solhaug, A., Vines, L.L., Ivanova, L., Spilsberg, B., Holme, J.A., Pestka, J., Collins, A., Eriksen, G.S., 2012. Mechanisms involved in alternariol-induced cell cycle arrest. Mutation research 738-739, 1-11.

Steigemann, P., Wurzenberger, C., Schmitz, M.H., Held, M., Guizetti, J., Maar, S., Gerlich, D.W., 2009. Aurora B-mediated abscission checkpoint protects against tetraploidization. Cell 136, 473-484.

Szafer-Glusman, E., Giansanti, M.G., Nishihama, R., Bolival, B., Pringle, J., Gatti, M., Fuller, M.T., 2008. A role for very-long-chain fatty acids in furrow ingression during cytokinesis in Drosophila spermatocytes. Current biology : CB 18, 1426-1431.

Tapia-Alveal, C., Outwin, E.A., Trempolec, N., Dziadkowiec, D., Murray, J.M., O'Connell, M.J., 2010. SMC complexes and topoisomerase II work together so that sister chromatids can work apart. Cell Cycle 9, 2065-2070.

Taylor, W.R., Stark, G.R., 2001. Regulation of the G2/M transition by p53. Oncogene 20, 1803-1815.

Toettcher, J.E., Loewer, A., Ostheimer, G.J., Yaffe, M.B., Tidor, B., Lahav, G., 2009. Distinct mechanisms act in concert to mediate cell cycle arrest. Proc Natl Acad Sci USA 106, 785-790.

Toyoshima-Morimoto, F., Taniguchi, E., Shinya, N., Iwamatsu, A., Nishida, E., 2001. Polo-like kinase 1 phosphorylates cyclin B1 and targets it to the nucleus during prophase. Nature 410, 215-220.

Vindelov, L.L., Christensen, I.J., Nissen, N.I., 1983. A detergent-trypsin method for the preparation of nuclei for flow cytometric DNA analysis. Cytometry 3, 323-327.

Watrin, E., Peters, J.M., 2009. The cohesin complex is required for the DNA damage-induced G2/M checkpoint in mammalian cells. EMBO J 28, 2625-2635.

Wollenhaupt, K., Schneider, F., Tiemann, U., 2008. Influence of alternariol (AOH) on regulator proteins of cap-dependent translation in porcine endometrial cells. Toxicology Letters 182, 57-62. 
Zhou, H.R., Islam, Z., Pestka, J.J., 2005. Induction of competing apoptotic and survival signaling pathways in the macrophage by the ribotoxic trichothecene deoxynivalenol. Toxicological sciences : an official journal of the Society of Toxicology 87, 113-122.

\section{Figure legends:}

Fig 1: AOH reduces cell growth. Cells were treated with AOH $(15$ or $30 \mu \mathrm{M})$ for 24 or $48 \mathrm{~h}$. The cells were counted by using a flow cytometer. Each data point represents the mean \pm SEM of 3 replicates and is representative for at least 3 independent experiments. Significant $(\mathrm{p}<0.05)$ difference compared to control is indicated by an asterisk $(*)$.

Fig 2: AOH induces cell cycle arrest. Cells were treated with $\mathrm{AOH}$, stained with $\mathrm{PI}$ and subjected to cell cycle analysis by flow cytometry using the 585/20 nm (FL2-A) filter. (A) The cells were treated with $15-30 \mu \mathrm{M}$ AOH for $6-48 \mathrm{~h}$ prior to analysis of the cell cycle. The histograms are representative of 5-7 independent experiments. (B) Quantification of the cell cycle distribution. The results represent the mean \pm SEM of 5-7 independent experiments. Significant difference $(\mathrm{p}<0.05)$ compared to control is indicated by an asterisk $(*)$ as determined by paired t-test.

Fig 3: AOH reduces the number of mitotic cells. (A) Cells were treated with AOH $(30 \mu \mathrm{M})$ for 4-48 h, and analysed by flow cytometry for Histone H3 (S28) - Alexa Fluor 647 (675/12.5 nm filter; FL4-A) vs. cell cycle; PI (585/20 nm filter; FL2-A). Events above the dotted line represent cells positive for phosphorylated Histone H3 (S28). (B) Results represent the mean \pm SEM of 3 independent experiments. Significant difference $(\mathrm{p}<0.05)$ compared to control is indicated by an asterisk $(*)$.

Fig 4: $\mathrm{AOH}$ inhibits activation of the cell cycle regulators associated with the $\mathrm{G}_{2} / \mathrm{M}$ transition. (A) Cells were treated with $\mathrm{AOH}(30 \mu \mathrm{M})$ for $6-48 \mathrm{~h}$, and analysed for cyclin $\mathrm{B} 1$, p-cyclin B1 (S147) or p-cdc2 (Tyr15) by Western blot. (B) Quantification of the AOH induced expression of cyclin B1 and p-cdc2 analysed by Western blot. The data represent mean \pm SEM of 3 independent experiments. Significant difference $(\mathrm{p}<0.05)$ compared to

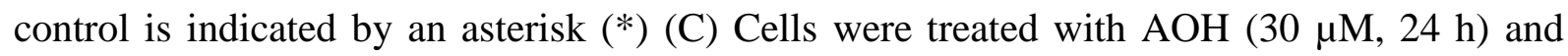


analysed for cyclin B1 and p-cdc-2 expression by flow cytometry, using anti-Alexa Fluor 647 as secondary antibody and the $675 / 12.5 \mathrm{~nm}$ filter (FL4-A) for analysis. Increased fluorescence, a shift to the right, represents increased expression of the protein. The data are representative for 3 independent experiments. (D) Cells were treated with AOH (30 $\mu \mathrm{M})$ for $24 \mathrm{~h}$ and analysed for cyclin B1 expression vs. cell cycle by flow cytometry. Single cells were selected (as shown in suppl. Fig S1) and cyclin B1 (Alexa Fluor 647; 675/12.5 nm filter, FL4A) vs. cell cycle (PI; 585/20 nm filter, FL2-A) were then analysed by flow cytometry. (E) Cells were treated with $\mathrm{AOH}(30 \mu \mathrm{M})$ for $24 \mathrm{~h}$, and analysed for cellular location of cyclin B1 by fluorescence microscopy.

Fig 5: AOH induces morphological changes of the nucleus. (A) Cells were treated with $\mathrm{AOH}(30 \mu \mathrm{M})$ for $48 \mathrm{~h}$, fixed in methanol and stained with Hoechst for fluorescence microscopic analysis. Scale bars represent $10 \mu \mathrm{m}$. (B) Cells were treated as above, for 24-72 h and cells with abnormal nuclear morphology counted. A minimum of 300 cells were counted per incubation. The results represent the mean of 2 independent experiments, were the error bars represent the difference of the two experiments. (C) The cells were treated with AOH (30 $\mu \mathrm{M}$ ) for $48 \mathrm{~h}$, fixed in methanol, stained with Hoechst and analyzed for MN by fluorescence microscopy. A minimum of 300 cells were counted per incubation. The results represent mean \pm SEM of 3 independent experiments. Significant difference $(\mathrm{p}<0.05)$ compared to control is indicated by an asterisk (*). (D) The cells were treated with AOH $(30 \mu \mathrm{M})$ for $48 \mathrm{~h}$ and analysed by TEM.

Fig 6: AOH induces polyploidy: (A) Cells were treated with $\mathrm{AOH}(30 \mu \mathrm{M})$ for time points as indicated and analysed for polyploidy by PI-staining (Vindelov) and flow cytometry. Single cells were selected (as shown in Suppl. Fig S1) and analysed for cell cycle distribution (PI; 585/20 nm filter, FL2-A). (B) Quantification of polyploidy analysed by flow cytometry. Results represent the mean \pm SEM of 3 independent experiments. Significant difference $(\mathrm{p}<$ 0.05) compared to control is indicated by an asterisk (*). Significance is calculated by using paired t-test.

Fig 7: AOH exposure leads to abnormal Aurora B bridges during cytokinesis. Cells were treated with $\mathrm{AOH}(30 \mu \mathrm{M})$ for $24 \mathrm{~h}$ and analysed for Aurora B (Alexa Fluor 488, green), $\alpha$ - 
tubulin (CY3, red) and Hoechst (nucleus, grey) by confocal microscopy. A. Normal Aurora B Bridge. B. Abnormal Aurora B bridge. C. Polyploidy. Scale bars represent $20 \mu \mathrm{m}$. A minimum of 300 cells were counted per incubation. Abnormal Aurora B bridges: Control: 0\% AOH: $1.7 \%$. The results are representative of 3 independent experiments.

\section{Supplemental figures}

Fig S1: Flow cytometric analysis of polyploidy. Cells were treated with $\mathrm{AOH}(30 \mu \mathrm{M})$ for $72 \mathrm{~h}$ and analysed for polyploidy by PI staining and flow cytometry. Debris was first excluded from all cells (gate 1) then single cells were selected by gating, FL-2A (areal)/FL-2W (with) (gate 2). The lower diagrams show the polyploidy cells presented in a cell cycle diagram or in a dot plot (size vs. DNA content).

Fig S2: p27 and cyclin D1 expression in response to AOH. The cells were treated with $\mathrm{AOH}(30 \mu \mathrm{M})$ for 6-48 h, and analysed by Western blot for expression of p27 and cyclin D1.

Fig 3S: Membrane remodelling and fluidity. The cells were treated with $\mathrm{AOH}(30 \mu \mathrm{M})$ for 24 h. (A) Pictures of fixed cells stained with Alexa Fluor 488 (green)-conjugated cholera toxin subunit B (Ctx B) to visualize ganglioside GM1 (a specific marker of lipid rafts), and co-stained with DAPI to detect nuclei. (A) The S order parameter of bulk membranes, which is inversely related to membrane fluidity, was measured by a spin-labelling method using EPR. The results represent mean \pm SEM of three independent experiments. $\mathrm{AOH}$ treated cells were significantly different from control $(\mathrm{p}<0.05)$ analysed by paired t-test. 
Figure 1

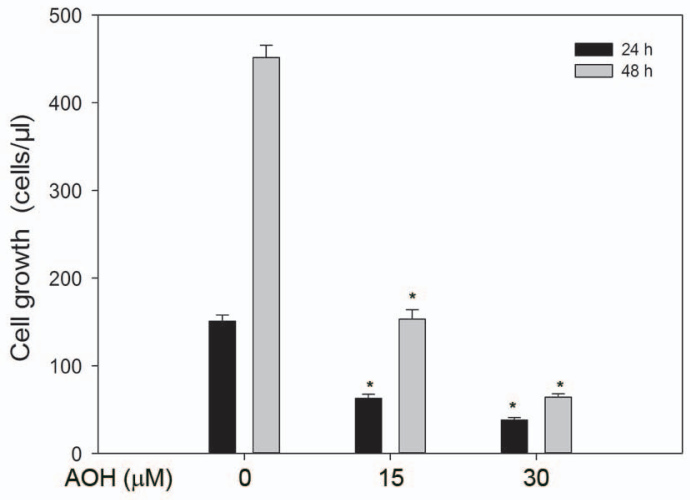


Figure 2

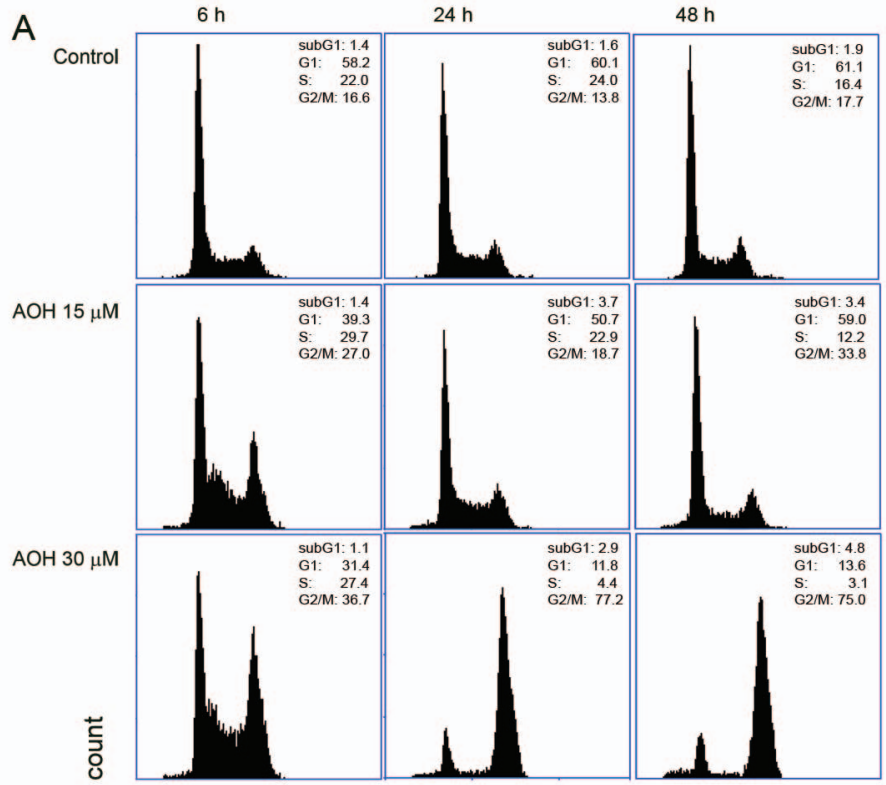

DNA content 


\section{Figure 2}
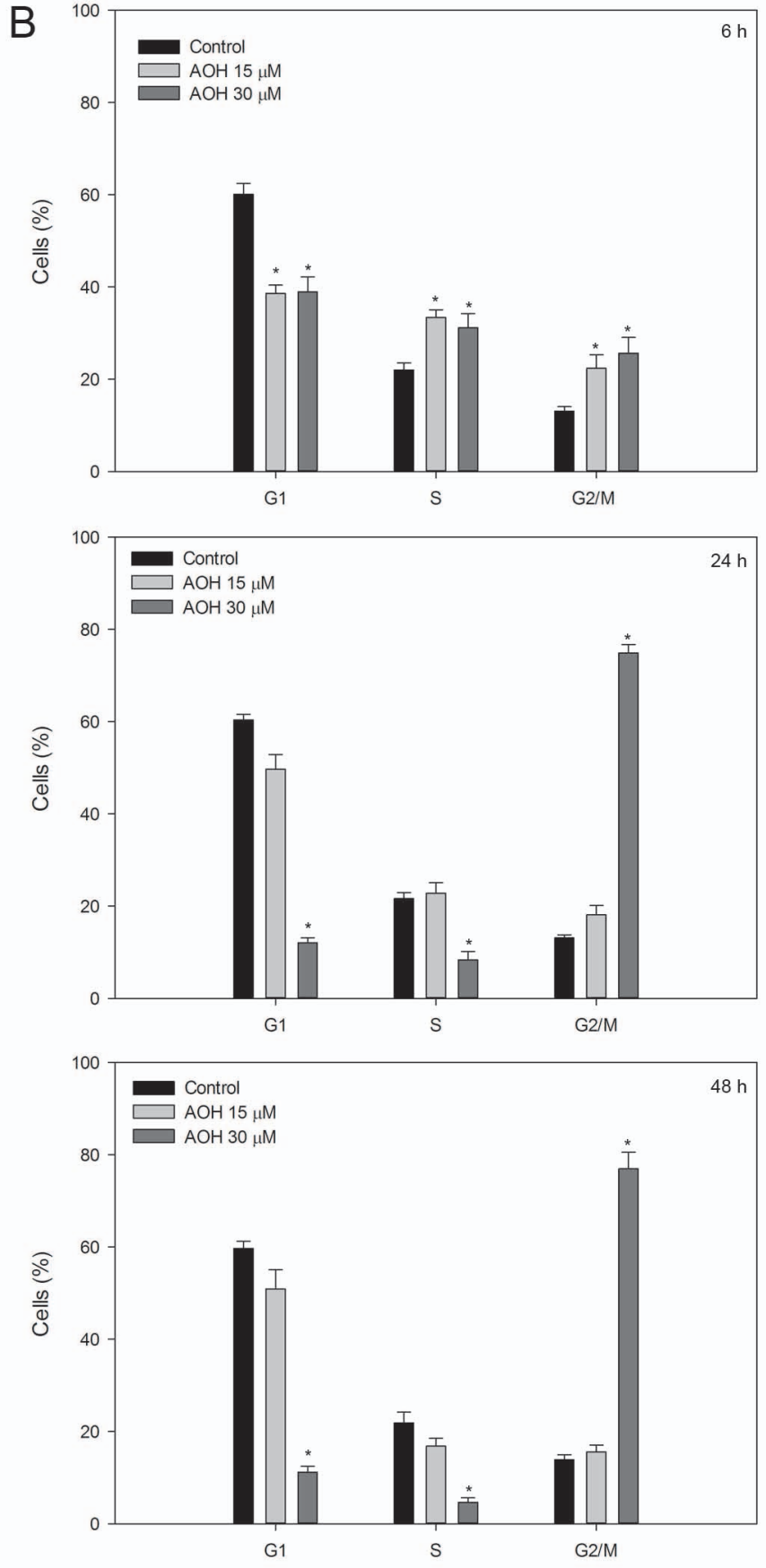
Figure 3

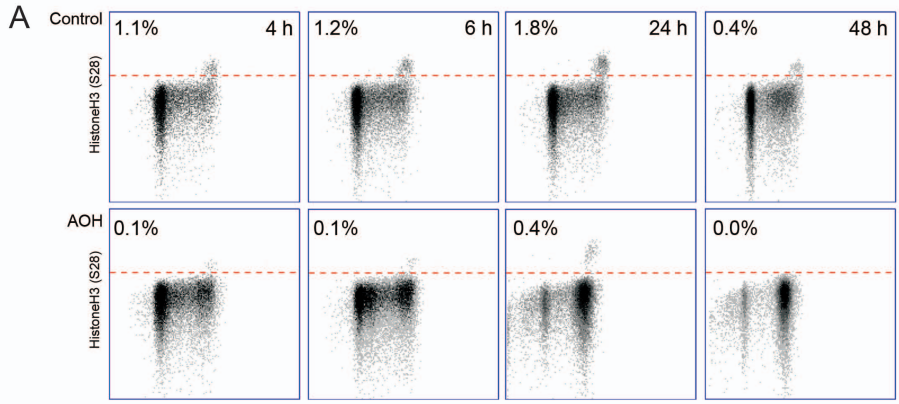

DNA content

B

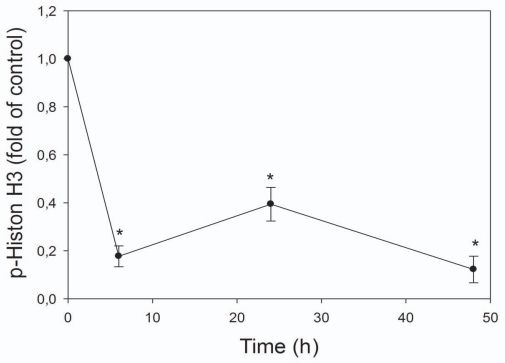


A

cyclin B1

$\beta$-actin

p-cyclin B1

$\beta$-actin

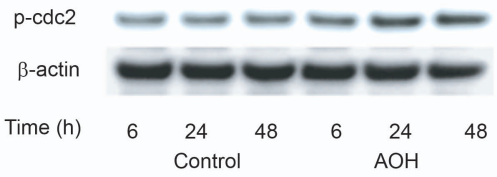

B
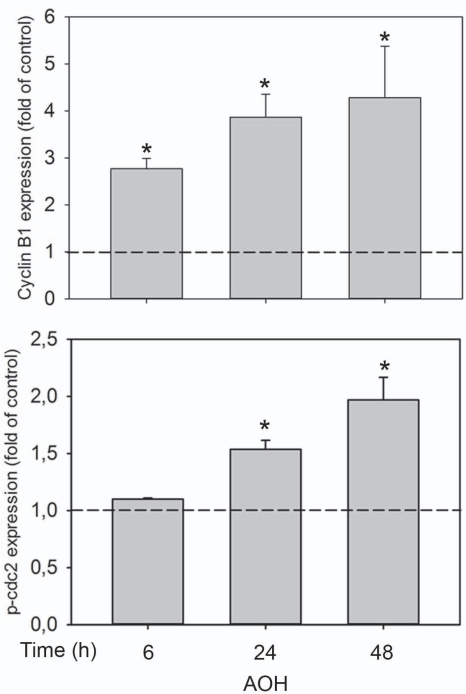
C

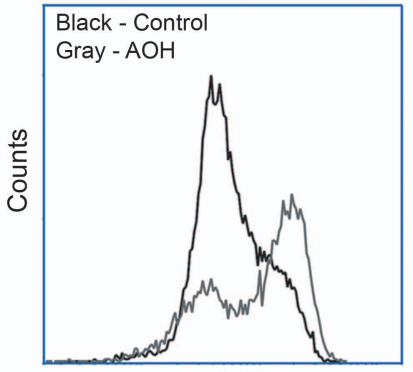

cyclin B1

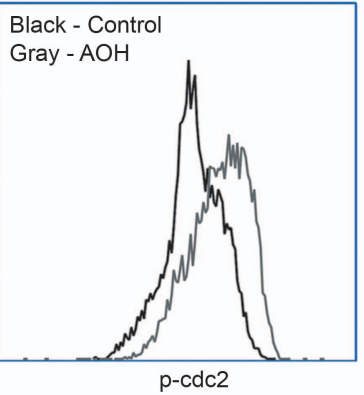

D

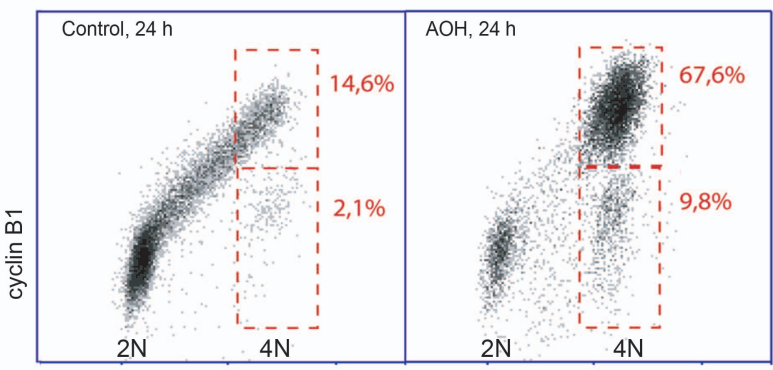

DNA content

E

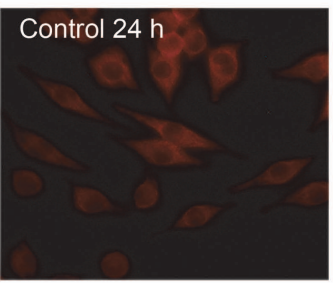

$\mathrm{AOH} 30 \mu \mathrm{M} 24 \mathrm{~h}$ 
Figure 5 A
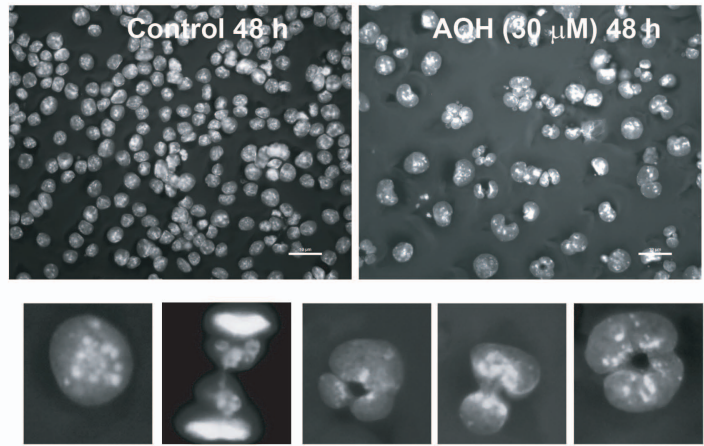

Normal
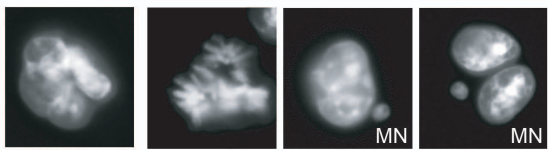

Abnormal nuclei

B

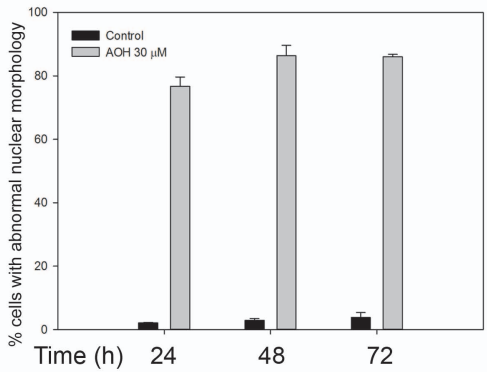

C

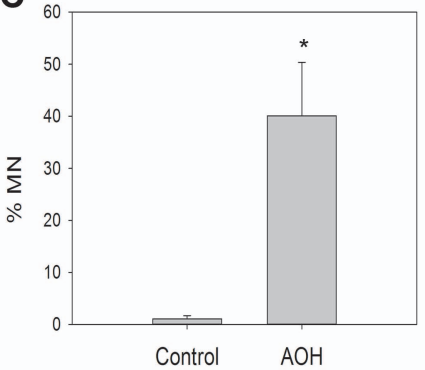

D

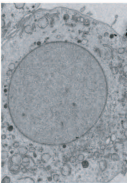

Normal
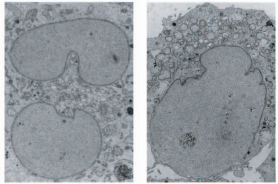

Abnormal nuclei

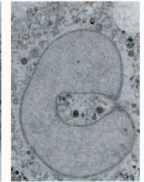


Figure 6

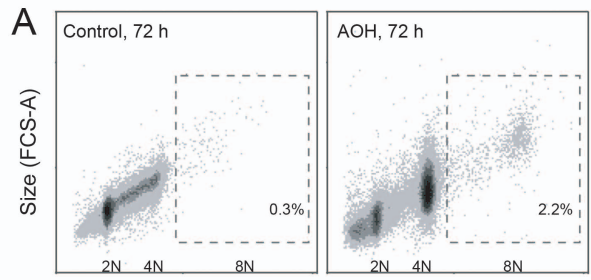

DNA content

B

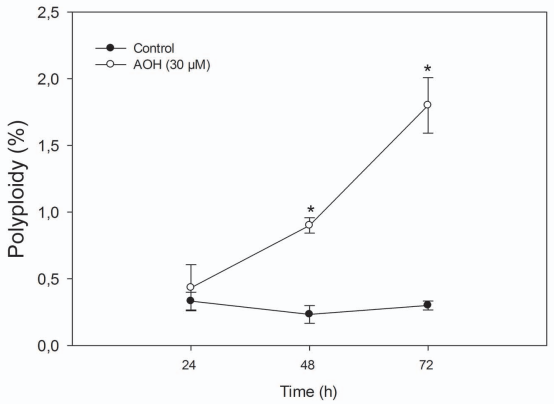


Figure 7
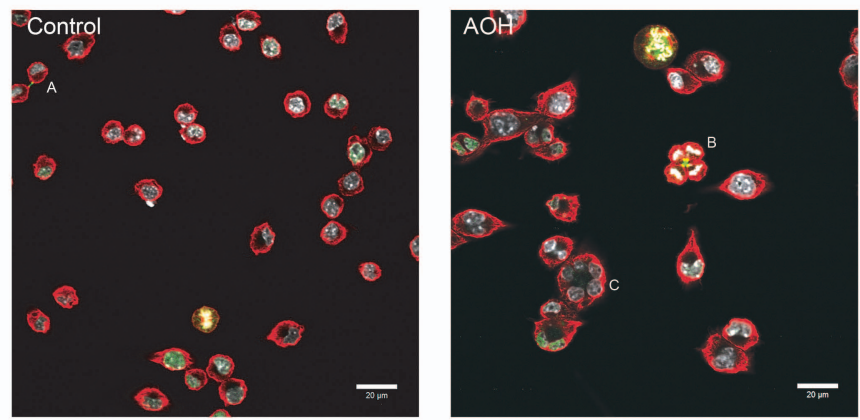


\section{Figure S1}
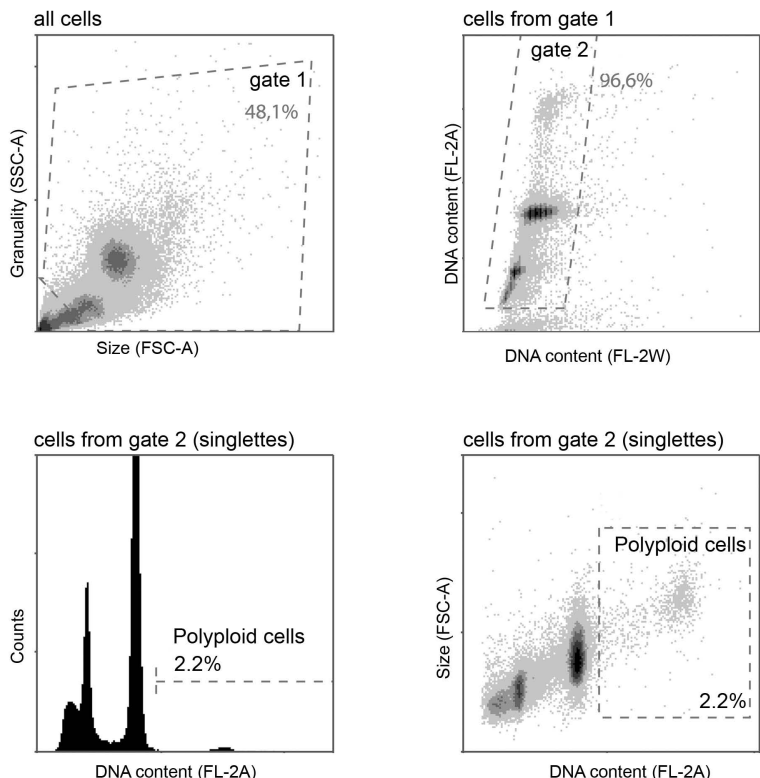

DNA content (FL-2A)

DNA content (FL-2A) 
Figure S2

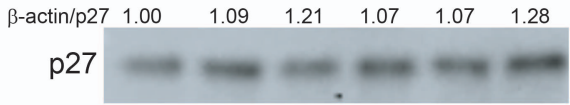

$\beta$-actin

$\begin{array}{lllllll}\beta \text {-actin/cyclin D1 } & 1.00 & 1.17 & 1.35 & 1.20 & 1.27 & 1.33\end{array}$

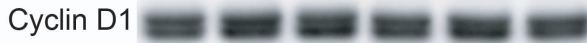

$\beta$-actin

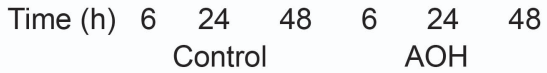




\section{Figure S3}

A

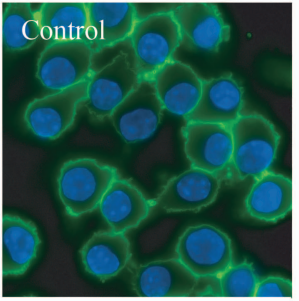

\section{$\mathrm{AOH}$}

B

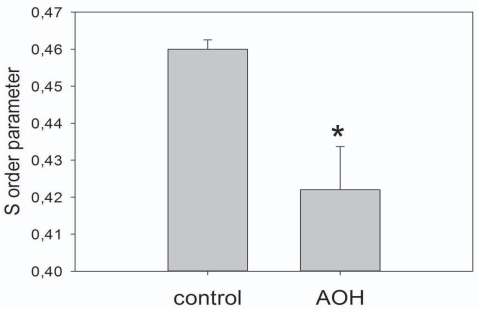

